\title{
REVERSION OF HÖLDER TYPE INEQUALITIES FOR SUMS OF WEIGHTED NORMS AND ADDITIVE WEIGHTED ESTIMATES OF INTEGRAL OPERATORS
}

\author{
R. OINAROV
}

Abstract. The additive weighted estimate $\|u K f\|_{q} \leqslant C\left(\|\rho f\|_{p}+\|v H f\|_{p}\right), f \geqslant 0$, where $K f(x)=\int_{0}^{x} K(x, s) f(s) d s, K(x, s) \geqslant 0, H f(x)=\int_{0}^{x} f(s) d s$ is reduced to the two-weighted estimate: $\|u K f\|_{q} \leqslant C\left\|\rho^{*} f\right\|_{p}, f \geqslant 0$, where the weight function $\rho^{*}$ is expressed via the weight functions $\rho$ and $v$.

Mathematics subject classification (2000): 26D15, 47A30, 47B38.

Key words and phrases: integral operators, weighted norms, additive weighted estimates, reversion of Hölder type inequalities.

\section{REFERENCES}

[1] R. OINAROV, Weighted inequalities for one class of integral operators (Russian), Doklady Akad. Nauk SSSR, (5), 1319, (1991), 1076-1078.

[2] R. OINAROV, On one three - weighted generalization of Hardy inequality (Russian), Matematicheskie zametki, (2), 54, (1993), 56-62.

[3] R. OINAROV AND A. A. Chagirov, Three - weighted inequalities with integral operators (Russian), Doklady Nats. Akad. Nauk Resp. Kaz., (2), (1993), 13-16.

[4] R. Oinarov and S. S. SAGintaEva, On one Hardy type three - weighted inequality (Russian), Science and education of South Kazakhstan, Series: economics, math., (6), (1997), 183-194.

[5] O. D. APYSHEV AND M. OTELBAEV, On convolution of one differential operator class and some theorems of imbedding (Russian), Izvestiya Akad. Nauk SSSR, Ser.: matem., (4), 43, (1997), 739-764.

[6] E. N. BATUEV, On theorems of imbedding and compactness of one class with weighted norms (Russian), Preprint VC DVO AN SSSR, (1989), 1-25.

[7] R. OINAROV, Two - sided estimates of one class of integral operators (Russian), Trudy Mat. Inst. Steklov RAN, 204, (1993), 240-250.

[8] V. D. StEPANOv, Weighted norm inequalities for integral operators and related topics, Nonlinear Analysis, Function Spaces and Applications, 5, (Proceedings of the Spring School hold in Prague, May 23-28), (1994), 135-175.

[9] B. OpIC AND A. KufNer, Hardy type inequalities, Pitman Research Notes in Mathematics (John Wiley, New York), (1990).

[10] E. T. SAWYER, Boundedness of classical operators in classical Lorents spaces, Studia Math., 96, (1990), $145-158$.

[11] H. P. HeInIG AND V. D. StePAnov, Weighted Hardy inequalities for increasing functions, Canad. J. Math., (1), 45, (1993), 104-116.

[12] M. L. Goldman, H. P. HeInIG AND V. D. STEPanov, On the principle of duality in Lorents spaces, Canad. J. Math., 48, (1996), 959-979. 